\title{
Tracking the Local Structure Change during the Photoabsorption Processes of Photocatalysts by the Ultrafast Pump-Probe XAFS Method
}

\author{
Yohei Uemura ${ }^{1, \dagger}$, Toshihiko Yokoyama ${ }^{1}$, Tetsuo Katayama ${ }^{2,3}$, Shunsuke Nozawa ${ }^{4}$ \\ and Kiyotaka Asakura $5, *$ (D) \\ 1 Institute for Molecular Science, Myodaiji-cho, Okazaki, Aichi 444-8585, Japan; \\ yohei.uemura@psi.ch (Y.U.); yokoyama@ims.ac.jp (T.Y.) \\ 2 Japan Synchrotron Radiation Research Institute, Kouto 1-1-1, Sayo, Hyogo 679-5198, Japan; \\ tetsuo@spring8.or.jp \\ 3 RIKEN SPring-8 Center, Kouto 1-1-1, Sayo, Hyogo 679-5148, Japan \\ 4 Institute of Materials Structure Sciences, High Energy Accelerator Research Organization, Oho 1-1, Tsukuba, \\ Ibaraki 305-0801, Japan; noz@post.kek.jp \\ 5 Institute for Catalysis and Division of Quantum Science and Engineering, Graduate School of Engineering, \\ Hokkaido University, Kita 21-10, Sapporo, Hokkaido 001-0021, Japan \\ * Correspondence: askr@cat.hokudai.ac.jp \\ + The current address of this author: Laboratory for Environmental Chemistry (LUC), Paul Scherrer Institute, \\ PSI, Forschungsstrasse 111, 5232 Villigen, Switzerland.
}

Received: 10 October 2020; Accepted: 2 November 2020; Published: 4 November 2020

Featured Application: Ultrafast pump-probe XAFS investigation of photocatalysts.

\begin{abstract}
The birth of synchrotron radiation (SR) facilities and X-ray free electron lasers (XFELs) has led to the development of new characterization tools that use X-rays and opened frontiers in science and technology. Ultrafast X-ray absorption fine structure (XAFS) spectroscopy for photocatalysts is one such significant research technique. Although carrier behavior in photocatalysts has been discussed in terms of the band theory and their energy levels in reciprocal space (k-space) based on optical spectroscopic results, it has rarely been discussed where photocarriers are located in real-space (r-space) based on direct observation of the excited states. XAFS provides information on the local electronic and geometrical structures around an X-ray-absorbing atom and can address photocarrier dynamics in the r-space observed from the X-ray-absorbing atom. In this article, we discuss the time dependent structure change of tungsten trioxide $\left(\mathrm{WO}_{3}\right)$ and bismuth vanadate $\left(\mathrm{BiVO}_{4}\right)$ photocatalysts studied by the ultrafast pump-probe XAFS method in the femtosecond to nanosecond time scale with the Photon Factory Advanced Ring (PF-AR) and the SPring-8 Angstrom Compact free-electron LAser (SACLA). $\mathrm{WO}_{3}$ shows a femtosecond decay process of photoexcited electrons followed by a structural change to a metastable state with a hundred picosecond speed, which is relaxed to the ground-state structure with a nanosecond time constant. The $\mathrm{Bi}_{3}$ edge of $\mathrm{BiVO}_{4}$ shows little contribution of the $\mathrm{Bi} 6 \mathrm{~s}$ electron to the photoabsorption process; however, it is sensitive to the structural change induced by the photoexcited electron. Time-resolved XAFS measurements in a wide range time domain and with varied wavelengths of the excitation pump laser facilitate understanding of the overall details regarding the photocarrier dynamics that have a significant influence on the photocatalytic performance.
\end{abstract}

Keywords: pump-probe XAFS; XFEL; photocatalyst; arrival timing monitor 


\section{Introduction}

The X-ray absorption fine structure (XAFS) method has been developed over the past half century according to the progress of X-ray sources. In particular, its time resolution has been improved significantly. In the early days of XAFS experiments (i.e., in the 1970s before the birth of synchrotron radiation (SR) facilities), it took a couple of days or more than a week to obtain a XAFS spectrum with a good signal-to-noise $(\mathrm{S} / \mathrm{N})$ ratio due to the low $\mathrm{X}$-ray flux of standard X-ray tubes. SR facilities were the first game-changer to make the measurement time of XAFS much shorter. It became possible to measure an XAFS spectrum with a good $\mathrm{S} / \mathrm{N}$ ratio in less than $1 \mathrm{~h}$ in the 1980 s using SR facilities. Further progress was achieved by the development of fast data acquisition techniques such as quick XAFS (QXAFS) [1] and dispersive XAFS (DXAFS) [2], which improved the time resolution down to the millisecond region in the 1990s. It is presently possible to measure an XAFS spectrum with a time resolution equal to or less than millisecond order [3,4]. Although the time resolution of XAFS has been reduced by an order of approximately $10^{8}$ compared to its early days, it is usually limited by the physical motion of X-ray optics for QXAFS or the response of data acquisition systems for QXAFS and DXAFS. Although there were transient XAFS methods to observe faster phenomena that happen within an order of milliseconds [5-7], it was difficult to reduce the time resolution below a single nanosecond. To go beyond this limitation, the pump-probe XAFS method was developed in the early 2000s, and could provide dynamics of materials in a time resolution of nanoseconds or less [8-12]. X-rays coming from an SR are pulses with finite pulse width (typically ca. 100 ps). Such a short pulse feature enables the dynamics of materials to be tracked during the photoinduced states by XAFS spectra as a function of the delay time between the pump (excitation) and the probe (detection). The time resolution in SR facilities is limited by the pulse duration of the X-ray pulse because the pulse duration of an excitation laser (100 fs) is typically much shorter than the X-ray pulse duration (ca. $100 \mathrm{ps).} \mathrm{The} \mathrm{advent} \mathrm{of} \mathrm{very} \mathrm{short} \mathrm{pulse} \mathrm{X-ray} \mathrm{sources} \mathrm{such} \mathrm{as} \mathrm{the} \mathrm{X-ray} \mathrm{free} \mathrm{electron} \mathrm{laser} \mathrm{(XFEL)}$ has extended the horizon of the pump-probe XAFS to the femtosecond region [13]. The high peak intensity enables the application of XAFS techniques such as high energy resolution fluorescence detected X-ray absorption near edge structure (HERFD-XAFS) [14,15] or resonant inelastic X-ray spectroscopy (RIXS) [16-18].

In this short review, we describe our studies on the photoexcitation processes of the tungsten trioxide $\left(\mathrm{WO}_{3}\right)$ and bismuth vanadate $\left(\mathrm{BiVO}_{4}\right)$ photocatalysts by pump-probe XAFS in SR and XFEL [19-22] over the last decade. The behavior of photocarriers in photocatalysts has been discussed in terms of band theory. The electron in the valence band mainly composed of oxygen atoms is photoexcited to the conduction band mainly composed of cations. The created photocarriers (electron in the conduction band or hole in the valence band) travel to the surface and react with substances [23-25]. Most experimental data have been obtained by optical spectroscopic techniques, which provide information regarding the energy levels of photocarriers in the reciprocal space (k-space). On the other hand, the location of photocarriers in real-space (r-space) has rarely been discussed based on the direct observation of photocatalysts after photoexcitation. XAFS provides information on the local electronic and geometrical structures around the X-ray absorbing atom. Therefore, XAFS can address photocarrier dynamics in the r-space around the $X$-ray absorbing atom $[15,26,27] . \mathrm{WO}_{3}$ and $\mathrm{BiVO}_{4}$, to which we have applied the pump-probe XAFS, comprise a Z-scheme photocatalyst system that mimics a photosynthesis system [28-30]. In the $\mathrm{W} \mathrm{L}_{3}$ edge of $\mathrm{WO}_{3}$, we mainly followed the excited electron and the local structure of $\mathrm{W}$ induced by the excited electron while the $\mathrm{Bi}_{3}$ edge of $\mathrm{BiVO}_{4}$ was expected to provide the behavior of the hole and the related local structure change around Bi. We discuss the photoinduced processes and demonstrate the importance of the wide time scale and the varied excitation energy measurements [19-22]. The photoexcited electron is revealed to be localized at the bottom of the conduction band, which induces distortion around the cation to stabilize itself. Finally, we discuss the future directions for pump-probe XAFS experiments. 


\section{Materials and Methods}

$\mathrm{WO}_{3}$ (particle size $<200 \mathrm{~nm}$ ) and $\mathrm{BiVO}_{4}$ (particle size ca. $200 \mathrm{~nm}$ ) were prepared as described elsewhere $[28,30,31]$. The nanoparticles were dispersed in distilled water. The concentrations of the suspensions were adjusted to obtain an appropriate optical length for the pump laser to pass through the suspensions. A typical concentration was ca. $1 \mathrm{mmol} \mathrm{L}^{-1}$.

Figure 1 shows the pump-probe XAFS setup at NW14A in the Photon Factory Advanced Ring (PF-AR) $[9,20]$. PF-AR is a $6.5 \mathrm{GeV}$ electron storage ring and its ring current is typically $50 \mathrm{~mA}$. PF-AR is always operated in a single bunch mode, i.e., only a single electron bunch circulates in the storage ring. This isolated electron bunch creates an X-ray pulse of which the pulse duration is ca. 100 ps with a $1.26 \mu$ s interval. The NW14A beamline is dedicated to the time resolved X-ray sciences. Besides pump-probe XAFS measurements [19-22,32,33], X-ray liquid scattering [34,35], X-ray diffraction [36], and X-ray single crystallography [37] techniques have been developed and have contributed to significant scientific achievements. There are two femtosecond lasers available to excite samples for pump-probe XAFS measurements. One is a Ti-sapphire laser with a regenerative amplifier that provides laser pulses up to $800 \mu \mathrm{J} /$ pulse at $800 \mathrm{~nm}$ with a repetition rate of $946 \mathrm{~Hz}$. The other is a high-repetition rate laser of which the fundamental wavelength is $1030 \mathrm{~nm}$. The laser can be synchronized with each X-ray pulse in the PF-AR. This laser enables high repetition data acquisition experiments to be conducted, which significantly improves the $\mathrm{S} / \mathrm{N}$ ratio of transient $\mathrm{XAFS}$ signals [38]. This high repetition scheme is effective for the measurement of the pump-probe extended X-ray absorption fine structure (EXAFS) and transient XAFS of extremely dilute samples or samples with a small X-ray absorption cross section, such as $\mathrm{L}_{1}$ edge XAFS.

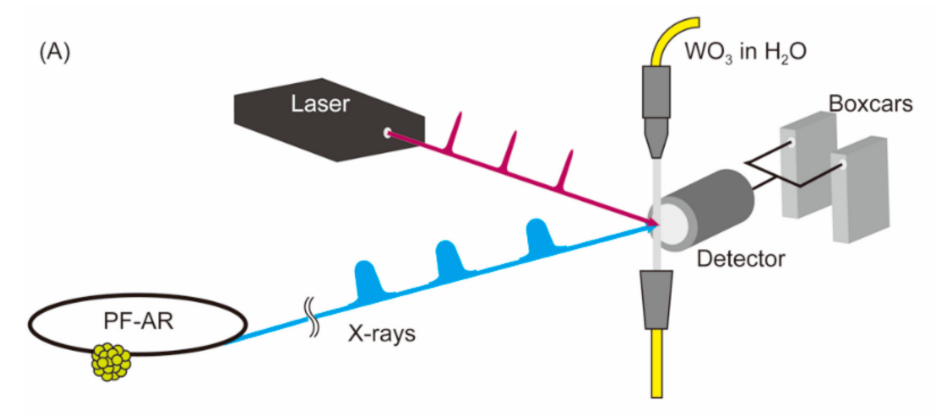

(B)

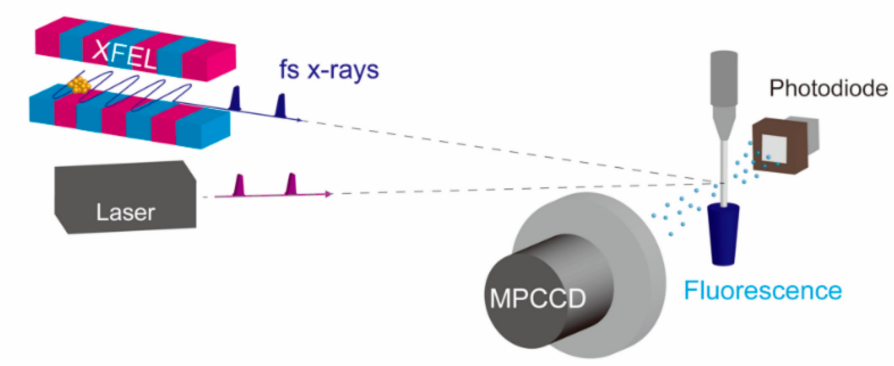

Figure 1. Schematic illustration of the pump-probe X-ray absorption fine structure (XAFS) setups at (A) NW14, Photon Factory Advanced Ring (PF-AR), and (B) EH2, BL3 at SPring-8 Angstrom Compact free electron LAser (SALCA).

Frequency-doubled laser pulses of the Ti-sapphire laser $(400 \mathrm{~nm})$ were used to excite the sample in the $\mathrm{W} \mathrm{L}_{3}$-edge XAFS experiments. The focal size of the laser on the sample was ca. $0.6 \mathrm{~mm}$ and its pulse duration was approximately $1 \mathrm{ps}$, and the laser fluence was estimated to be $280 \mathrm{~mJ} \cdot \mathrm{cm}^{-2}$. A photomultiplier tube with a plastic scintillator was employed as an X-ray detector and two boxcar integrators were used to separately accumulate pumped and unpumped XAFS signals. The $\mathrm{WO}_{3}$ suspension was circulated continuously using a magnet-gear pump and produced a $500 \mu \mathrm{m}$ liquid 
jet on the sample position where the pump laser and the probe X-ray source were overlapped with each other.

A high repetition rate measurement scheme was employed for the $W L_{1}$-edge and $B i L_{3}$-edge XAFS experiments. The third harmonics (ca. $343 \mathrm{~nm}$ ) of the high repetition laser was used to excite the sample with a fluence of ca. $35 \mathrm{~mJ} \cdot \mathrm{cm}^{-2}$. The X-ray was focused using an X-ray capillary lens to $\emptyset 100 \mu \mathrm{m}$ and the sample was a $300 \mu \mathrm{m}$ liquid jet.

The pump-probe experiments in the femtosecond and picosecond regions were conducted in the EH2 unit of BL3, SPring-8 Angstrom Compact free electron LAser (SALCA) [39,40]. SACLA generates intense X-ray pulses with a pulse duration less than $10 \mathrm{fs}$ at a repetition rate of $60 \mathrm{~Hz}$ [41]. These X-ray pulses are delivered evenly to BL2 and BL3, and consequently, the repetition rate of XFEL pulses in the pump-probe XAFS experiments is $30 \mathrm{~Hz}$. The low repetition rate of the SACLA has an advantage in the use of a commercial optical parametric amplifier for the excitation light source so that the excited wavelength can be easily selected. The EH2 unit has a platform [42] designed for ultrafast liquid chemistry, which covers several complementary X-ray techniques, e.g., pump-probe XAFS $[19,21,27,43,44]$, pump-probe X-ray emission spectroscopy (XES) [45], and pump-probe X-ray liquid scattering. The monochromatized X-ray pulses were focused with a Be compound refractive lenses (CRLs) [46] to give a beam size of $100 \times 100 \mu \mathrm{m}^{2}$ at the sample position. Two types of $\mathrm{X}$-ray detectors were utilized to measure the fluorescence X-ray intensity emitted from samples. One was a large 2-dimensional detector developed by RIKEN, Japan, which is referred to as a multi-port charge-coupled device (MPCCD) detector [47]. The other was a Si photodiode detector (Hamamatsu Photonics, S3590-09). The MPCCD can be utilized for various types of X-ray measurements. Each pixel in the MPCCD has an energy resolution $(<1 \mathrm{keV})$; therefore, the MPCCD can be used as an energy-dispersive detector similar to a solid state detector (SSD) or a silicon drift detector (SDD), which are widely used in XAFS beamlines. On the other hand, the photodiode detector produces a charge pulse upon the acceptance of a fluorescence X-ray photon, which is processed by charge-sensitive and shaping amplifiers. The output signals from the amplifiers are evaluated by a waveform fitting [48].

The incident X-ray intensity was measured with a transmissive intensity monitor for the normalization of the fluorescence $\mathrm{X}$-ray intensity. Inside the intensity monitor, there were photodiodes that measured X-ray intensity scattered by a polyimide or CVD film [42]. The frequency-doubled Ti-sapphire laser was employed as an excitation laser, where the pulse duration was $70 \mathrm{fs}$ and the estimated fluence at the sample position was $520 \mathrm{~mJ} \cdot \mathrm{cm}^{-2}$. The timing jitter between the excitation and X-ray laser pulses was typically $500 \mathrm{fs}$, which limited the time resolution. The timing jitter was corrected for the ultrafast experiment ( $\leq 100 \mathrm{fs}$ ) using an arrival-timing monitor (ATM) [49]. The ATM developed at the SACLA recorded the time difference between the probe X-ray and the pump laser pulses using the change of the transmittance of a gallium arsenide (GaAs) thin film by the irradiation of a short X-ray pulse. Analysis of the time difference for each X-ray pulse revealed the net delay time of the laser pulse. This post-data-processing improves the time resolution of the measurements. The time resolution using the ATM can be estimated as ca. $12 \mathrm{fs}$ [27,50]. (It should be noted that the actual time resolution is dependent on other factors of the experimental setup, such as the pulse duration of the pump laser and the thickness of the sample.)

\section{Results}

\subsection{Photoexcited States of $\mathrm{WO}_{3}$ in Femtosecond and Nanosecond Regions}

Figure 2 shows the $\mathrm{W} \mathrm{L}_{3}$-edge normalized XAFS spectrum of ground-state $\mathrm{WO}_{3}$ [20]. $\mathrm{WO}_{3}$ is known as a wide-bandgap semiconductor, of which the bandgap is ca. $2.4 \mathrm{eV}$. $\mathrm{WO}_{3}$ can promote the oxygen evolution reaction because of its valence band position [51], and this catalytic property is applied to a visible-light sensitive photocatalyst in the Z-scheme mechanism $[7,8]$. The peak at the X-ray absorption edge (called the white line) could be assigned to the transition from the $\mathrm{W}$ 
$2 p_{3 / 2}$ to $5 d$ orbitals. A strong white line appeared because $W$ is in the 6 -valent state, i.e., the $\mathrm{d}^{0}$ state. After excitation, the white line intensity decreased, as shown by the red curve in Figure 2 (XAFS at a delay of $150 \mathrm{ps}$ ). The change in the X-ray absorption intensity was recovered at around $10 \mathrm{~ns}$. This change could be simply explained by photoexcitation of the electron of $\mathrm{O} 2 \mathrm{p}$ at the valence band to the conduction band mainly composed of $\mathrm{W} 5 \mathrm{~d}$; however, this simple interpretation was rejected due to the following reason. The second derivative of $\mathrm{W} \mathrm{L}_{3}$-edge XAFS spectrum gave two peaks that correspond to the crystal field d-orbital splitting. If the local structure of $\mathrm{W}$ in $\mathrm{WO}_{3}$ was assumed to have an octahedral structure, then the $5 \mathrm{~d}$ orbitals were split into $t_{2 \mathrm{~g}}$ and $\mathrm{e}_{\mathrm{g}}$ orbitals, which appeared as two peaks in the second derivative [52]. The bottom of the conduction band was mainly constructed from the $t_{2 g}$ states. The spectral change seemed to be the occupation of the higher $e_{g}$ orbitals with the photoexcited electrons because the $\mathrm{e}_{\mathrm{g}}$ orbitals in the second derivative and the photoinduced change peak top coincided well, as shown in Figure 2. However, it was not possible to excite the electron at the valence band to the higher $e_{g}$ orbital, because the energy difference between the two was much greater than the photon energy of the pump laser. We could not explain why the photoinduced electron was not located at the bottom of the conduction band but at the higher level. The transient XAFS at a delay of $150 \mathrm{ps}$ should be a secondary state after the structural change and the rearrangement of the density of states. The primary process could not be observed with the time resolution of the PF-AR.

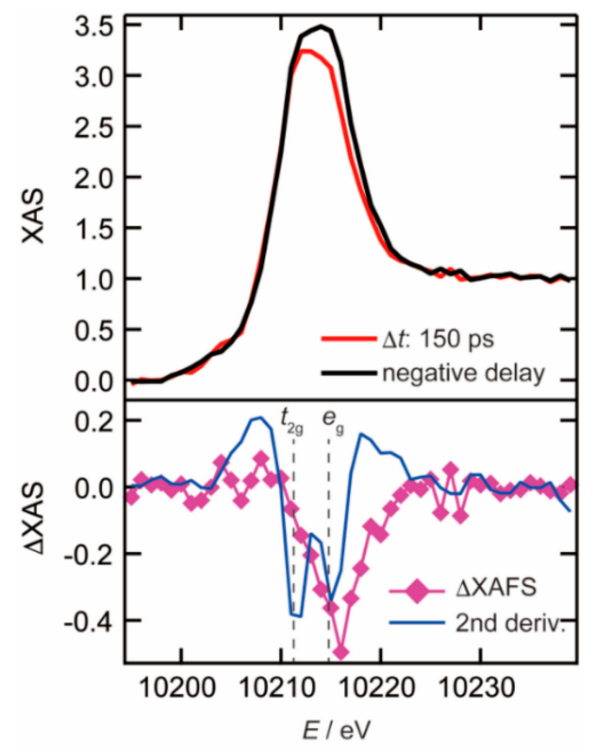

Figure 2. $\mathrm{W} \mathrm{L}_{3}$ edge XAFS spectra for $\mathrm{WO}_{3}$ before (black) and after (red) photoexcitation (top panel), and difference XAFS spectrum of photoexcited $\mathrm{WO}_{3}$ and a 2nd derivative of the XAFS of $\mathrm{WO}_{3}$ (blue in bottom panel). (The figure is reproduced from [20] with permission of Chemical Society of Japan).

Picosecond-order pump-probe XAFS experiments were conducted with the SACLA to observe the hidden primary process. Difference spectra at several delays are shown in Figure 3. The time resolution was ca. $500 \mathrm{fs}$ due to the presence of time jitter [42,50]. Three distinctive peaks were observed in the difference spectra, as shown in Figure 3a. A rise peak $A$ at 11,206 eV and a bleach peak $C$ at 11,211 eV appeared at a delay of $500 \mathrm{fs}$ together with a smaller peak B in-between. The rise peak at A was not observed in the previous experiments conducted at the PF-AR. The rise and bleach features arose from the spectral shift to lower energy. When the pump laser excited an $\mathrm{O} 2 \mathrm{p}$ valence electron to the conduction band consisting of $W$ orbitals, the $W$ valence state should be reduced to $5+$, which induces the $\mathrm{W} \mathrm{L}_{3}$ edge shift. The first derivative multiplied by the energy shift $(\Delta E=0.4 \mathrm{eV}), \Delta \mu=\frac{\mathrm{d} \mu}{\mathrm{d} E} \times \Delta E$, agreed well with the difference spectrum at the peak positions at A and C [21]. However, peak $A$ was smaller than the peak height expected from the first derivative. The smaller intensity than that expected could be explained by filling of the $t_{2 g}$ state with the photoexcited electron which was located at the bottom of the conduction band. In the following process, the magnitude of peak A decreased 
with the increase in the magnitude of peak $C$ by 200 ps, which suggests that the structural change formed a metastable $\mathrm{WO}_{3}$ state. Peak $\mathrm{C}$ gradually recovered to its initial value with a similar decay rate of nanosecond order as observed with the PF-AR.
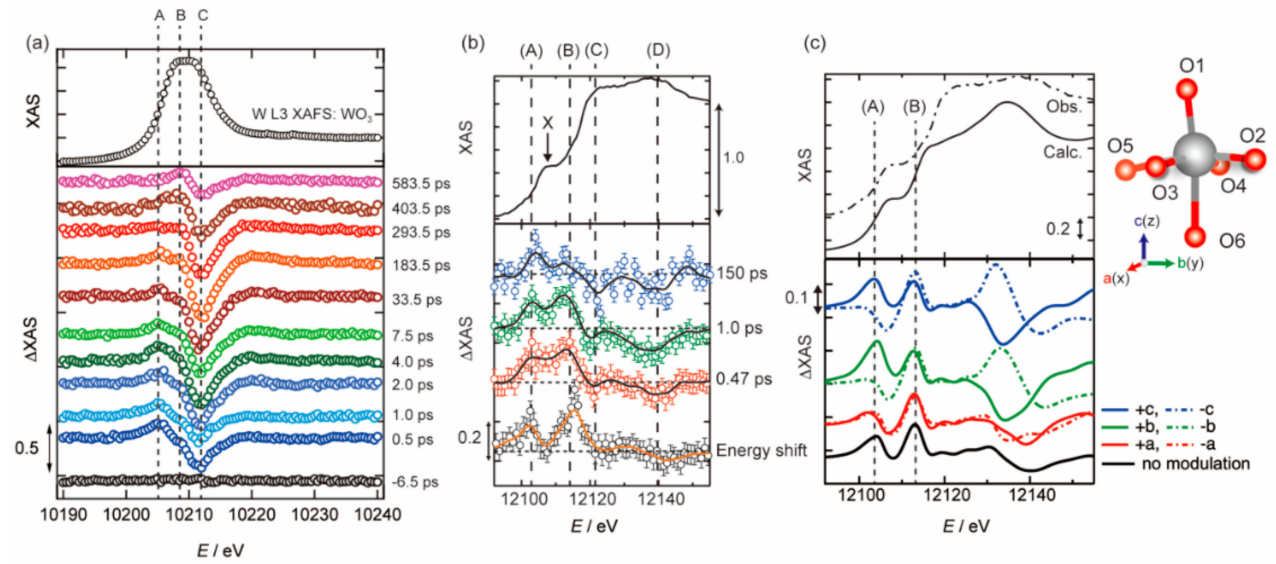

Figure 3. (a) $\mathrm{W} \mathrm{L}_{3}$ edge and (b) $\mathrm{W} \mathrm{L}_{1}$ edge difference spectra between the photoexcited (pumped) and the ground-state (unpumped) $\mathrm{WO}_{3}$ measured at SACLA. The upper panels of $(\mathbf{a}, \mathbf{b})$ show the raw spectra of ground-state $\mathrm{WO}_{3}$. (c) Theoretically calculated $\mathrm{L}_{1}$ edge difference spectra using FPMS code with different model structures. (The figure was reproduced from [21] with permission of John Wiley and Sons and from [22] with permission of the Royal Chemical Society).

The $\mathrm{W} \mathrm{L}_{1}$ edge is sensitive to the structural change; therefore, an attempt was made to measure the $\mathrm{W} \mathrm{L}_{1}$ pump-probe XAFS, even though its $\mathrm{X}$-ray cross section was low. Figure $3 \mathrm{~b}$ shows the $\mathrm{W}$ $\mathrm{L}_{1}$-edge spectrum of the ground-state $\mathrm{WO}_{3}$ (upper panel) and its difference spectra (lower panel) at several delays. Two peaks, denoted as (A) and (B), appeared in the difference spectra. The bottom of the difference spectra labeled as the energy shift corresponded to the calculated difference spectra between that with and without the negative $1 \mathrm{eV}$ energy shift where the two peaks appeared at the corresponding positions of (A) and (B). Consequently, peaks (A) and (B) were mainly caused by the edge shift due to the photoexcited electron transfer from $\mathrm{O}^{2-}$ to $\mathrm{W}^{6+}$. However, the intensity ratio between peak (A) and peak (B) changed significantly with time after the photoexcitation. The intensity of peak (A) became greater than that of peak (B) at 150 ps. The origin for the intensity ratio changes in peaks (A) and (B) could be attributed to the formation of the metastable state at $150 \mathrm{ps}$. Peak X in the upper panel of Figure $3 \mathrm{~b}$ was identified as the electron transition from the $2 \mathrm{~s}$ to the $5 \mathrm{~d}$ orbital. Although the $2 \mathrm{~s} \rightarrow 5 \mathrm{~d}$ transition was dipole-forbidden, the distortion from the $\mathrm{O}_{\mathrm{h}}$ symmetry allowed the hybridization of $5 \mathrm{~d}$ with $6 \mathrm{p}$ orbitals and a strong dipole transition occurred at peak X. Peak X is a good indicator for the structural distortion around $W$ [53]. Additionally, peak $X$ was shifted to lower energy just after the photoabsorption and increased by the subsequent distortion; therefore, the lower energy peak (A) in the difference spectrum should increase at $150 \mathrm{ps}$.

Although the difference spectra in Figure $3 \mathrm{~b}$ could be interpreted based on the knowledge of XAFS, it was difficult to elucidate how the local structure of $\mathrm{WO}_{3}$ changes after photoexcitation. The difference in the $\mathrm{W} \mathrm{L}_{1}$-edge XAFS at 150 ps was analyzed by conducting full-potential multiple scattering calculations using an FPMS code to understand more details of the local structural change of photoexcited $\mathrm{WO}_{3}$ [54]. The position of the central $\mathrm{W}$ atom was moved by $0.1 \AA$ from its original position along the three axes as shown in Figure 3c. The difference of the spectra was calculated based on the structures between distorted and original. The short bonds $\mathrm{W}-\mathrm{O}(1)(1.756 \AA)$ and $\mathrm{W}-\mathrm{O}(2)(1.767 \AA)$ were aligned along the $\mathrm{c}$ and $\mathrm{b}$ axes together with long $\mathrm{W}-\mathrm{O}(5)(2.107 \AA)$ and $\mathrm{W}-\mathrm{O}(6)$ $(2.173 \AA)$, respectively. The $+\mathrm{c}$ or $+\mathrm{b}$ movement corresponded to the $\mathrm{W}-\mathrm{O}(1)$ or $\mathrm{W}-\mathrm{O}(2)$ contraction and indicated the formation of a more distorted structure, while $-\mathrm{c}$ or $-\mathrm{b}$ corresponded to a less distorted structure. Peak (A) became larger only when the $\mathrm{W}$ moved in the $+\mathrm{c}$ or $+\mathrm{b}$ directions, which indicates enhancement of the distortion of $\mathrm{WO}_{3}$ as expected. 
Combining the results of $\mathrm{L}_{3}$ and $\mathrm{L}_{1}$ edge XAFS, the bottom of the conduction band mainly composed of $\mathrm{W} d$ states was partially filled with photoexcited electrons at less than 1 ps. In the molecular orbital pictures, $\mathrm{d}$ states at the bottom of the conduction bands corresponded to the lowest antibonding $\pi$-states that were accompanied with longer bonds. The filling of the lowest antibonding $\pi$-state made the longer bond weaker and elongated them so that the shorter bond became shorter to enhance the distortion. Consequently, distorted metastable $\mathrm{WO}_{3}$ was formed at $150 \mathrm{ps}$.

Although the initial photoexcited state of $\mathrm{WO}_{3}$ should be formed within a shorter time scale and should have a different electronic structure compared to its later time domain, we could not address the initial photoexcitation state of $\mathrm{WO}_{3}$ formed in the very early time $(<500 \mathrm{fs})$ due to the limitation of the time resolution of the experimental setup. The change of peaks $A$ and $C$ was observed with ATM to understand the electronic structure of $\mathrm{WO}_{3}$ in the early state of its photoexcited state [50]. Figure 4 shows the changes in the $X$-ray absorption intensity for peaks $\mathrm{A}(11,206 \mathrm{eV})$ and $\mathrm{C}(11,211 \mathrm{eV})$ in the $\mathrm{W} \mathrm{L}_{3}$-edge difference spectrum. The time resolution without ATM was estimated to be ca. $700 \mathrm{fs}$ from the rise of peak A and the fall of peak $C$. On the other hand, the time resolution with ATM in this experiment was estimated to be ca. $180 \mathrm{fs}$. Although there was no obvious difference observed in peak $\mathrm{C}$, except for the different time resolution around $0 \mathrm{fs}$, a new ultra-fast process was observed in peak A less than 1ps. The peak intensity grew by ca. $300 \mathrm{fs}$ and decreased by $600 \mathrm{fs}$. A time constant for this decay process was estimated as ca. 0.20(1) ps using a single exponential function. Without ATM, this fast process was smeared out because of the poor time resolution. No change in the time evolution of the peak $\mathrm{C}$ intensity with and without ATM meant that the electron transfer from the $\mathrm{O}$ to $\mathrm{W}$ site occurred in the very early stage of less than $180 \mathrm{fs}$. The sharp rise in peak A followed by the quick decay could be explained in terms of d-electron filling. The electrons at the very early stage may be excited not to the bottom of the conduction band but to the higher states of the conduction band, both of which are composed of W orbitals. After $180 \mathrm{fs}$, the extra energy of photoexcited electrons was released to relax to the bottom of the conduction band, which caused the reduction of peak A. A similar phenomenon was observed in hematite where the hot electron was relaxed within $200 \mathrm{fs}$ to form a small polaron [17].
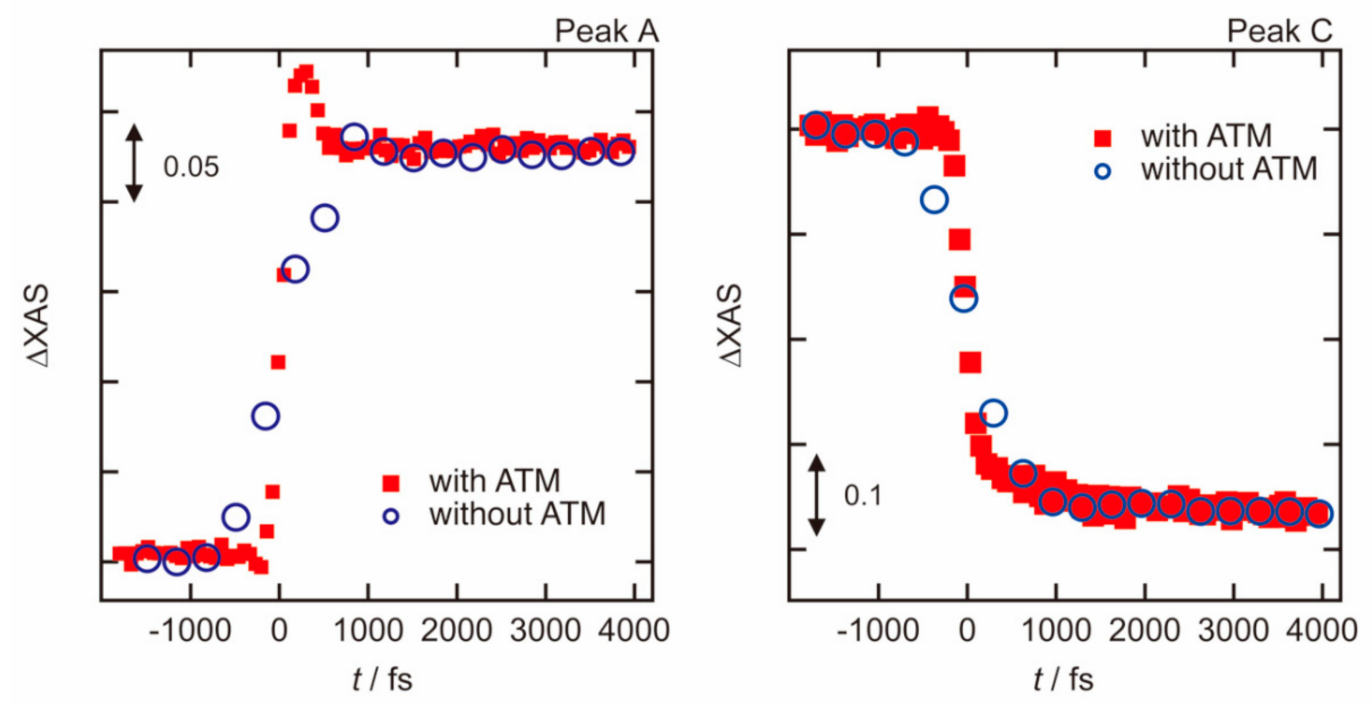

Figure 4. Kinetic traces of $\mathrm{X}$-ray absorption intensity at peak $\mathrm{A}$ and $\mathrm{C}$ in the $\mathrm{W} \mathrm{L}_{3}$ edge difference spectra.

In summary, the photoexcited state of $\mathrm{WO}_{3}$ was observed in a wide range of time domains (femtosecond, picosecond, and nanosecond). In less than the picosecond time domain, the photoexcited electron relaxed to the bottom of the conduction band mainly composed of the $\mathrm{W} d$ state. The electrons at the bottom of conduction band induced the structural distortion in the 100-200 ps time scale to create 
the metastable state. The metastable state was then relaxed to the ground-state in the nanosecond time scale.

\subsection{Photoexcited States of $\mathrm{BiVO}_{4}$}

Bismuth vanadate $\left(\mathrm{BiVO}_{4}\right)$ is a potential candidate for the fabrication of useful Z-scheme photocatalysts and/or photoelectrode systems due to the band gap of 2.4-2.6 eV and the valence band position [30,31,55-59]. Apart from improving the performance of $\mathrm{BiVO}_{4}$ by the development of novel synthetic methods $[30,31,55-58]$, the nature of its photocatalytic activity has been investigated [60-66]. For example, density functional theory (DFT) calculations have been performed to gain insight into the ground-state electronic structure of $\mathrm{BiVO}_{4}$ and to elucidate the properties of excited-state photocarriers $[60,61]$ and the behavior of photocarriers in femtosecond-microsecond time scales was investigated by transient spectroscopic methods [62-66]. However, there is still an open question of the electronic structure of $\mathrm{BiVO}_{4}$, in particular, the contribution of $\mathrm{Bi}$ atoms. It has been considered that $\mathrm{Bi}$ atoms contribute to the top of the valence band, which makes the bandgap narrower and results in higher photocatalytic efficiency. However, there has been no direct evidence that indicates the contribution of Bi atoms. XAFS can be used to elucidate the dynamics of $\mathrm{Bi}$ atoms in $\mathrm{BiVO}_{4}$ after photoexcitation because it monitors the $\mathrm{Bi}$ atoms selectively. In this context, pump-probe XAFS experiments on the photoexcited state of $\mathrm{BiVO}_{4}$ were performed with the PF-AR and SACLA.

Figure 5 shows $\mathrm{Bi} \mathrm{L}_{3}$ edge XANES of the ground-state $\mathrm{BiVO}_{4}$ (upper panel) and its difference spectra after photoexcitation. The main change at a delay of $2 \mathrm{ps}$ appeared around $13,443 \mathrm{eV}$, denoted as B in Figure 5, which subsequently exhibited gradual growth to achieve a maximum at 60 ps (Figure 5b). The changes around 13,430 and 13,460 eV (denoted as peaks A and C, respectively) increased afterwards with some delay from the change of peak $B$ and reached a maximum around a delay of $60 \mathrm{ps,} \mathrm{i.e.,} \mathrm{a} \mathrm{fast}$ X-ray absorption change was observed with a delay time of $1 \mathrm{ps}$ at peak $\mathrm{B}$, while little change was evident in peaks $\mathrm{A}$ and $\mathrm{C}$. The photoexcitation of $\mathrm{BiVO}_{4}$ comprises at least two distinct processes, i.e., the fast depletion at peak $B$ followed by slow magnitude growth of all peaks $A, B$, and $C$ up to 60 ps. Figure $5 b$ shows kinetic traces of the $X$-ray absorption coefficients for the $A, B$, and $C$ peaks. The second slow processes were fitted with a single exponential function, $y=\alpha \cdot \exp (-t / \tau)+\beta$.

The time constants $\tau$, for peaks A, B, and C were estimated to be $13 \pm 5 \mathrm{ps}, 14 \pm 2 \mathrm{ps}$, and $13 \pm 7 \mathrm{ps}$, respectively. The excited state was relaxed to the ground-state with a time constant of $40 \mathrm{~ns}$, which was measured at the PF-AR. According to a previous report [60,61], Bi 6s electrons are assumed to be excited to the conduction band by photoabsorption. If this were the case, then the Bi $\mathrm{L}_{3}$ edge XANES should have been shifted to higher energy. However, the difference XAFS at 2 ps could not be reproduced using the difference spectrum $\left(\delta \mu_{\text {Eshift }}\right)$ between $\mathrm{Bi} \mathrm{L}_{3}$-edge XAFS spectrum of the ground-state $\mathrm{BiVO}_{4}$ shifted to higher energy by $\Delta \mathrm{E}, \mu^{\mathrm{gs}}{ }_{\mathrm{L} 3}(E+\Delta E)$, and the original one, $\mu^{\mathrm{gs}}{ }_{\mathrm{L} 3}(E), \delta \mu_{\mathrm{Eshift}}=\mu^{\mathrm{gs}}{ }_{\mathrm{L} 3}(E+\Delta E)$ $-\mu^{\mathrm{gs}} \mathrm{L3}(E)[22]$.

This indicates that the electron density on Bi atoms is not varied to a significant extent after the primary photoabsorption process. In previous papers, coherent oscillations were observed in the early stage ( $<1 \mathrm{ps}$ ) of the photoexcitation of $\mathrm{BiVO}_{4}$ by optical spectroscopic measurements [62,63], which induced a dynamic local structural change around Bi atoms [59,62-64]. Therefore, it was inferred that the coherent oscillations could create peak $B$ in the $B i L_{3}$ edge difference XAFS spectrum. Peaks A and $C$, which gradually appeared, could be due to static distortion of the Bi structure because the $B i L_{3}$ edge feature is dominantly affected by the Bi-O bond distance, as pointed out by Nan and John [67]. XANES calculations were conducted using FEFF [22] for different Bi local configurations and the movement of $\mathrm{Bi}$ atoms toward $\mathrm{VO}_{4}$ units by $0.05 \AA$ was able to reproduce peaks $\mathrm{A}, \mathrm{B}$, and $\mathrm{C}$ in the difference spectra at a delay of $40 \mathrm{ps}$. Therefore, the slower process lasting by a delay of $40 \mathrm{ps}$ could be ascribed to a structural change of $\mathrm{Bi}-\mathrm{O}$ bond contraction. 

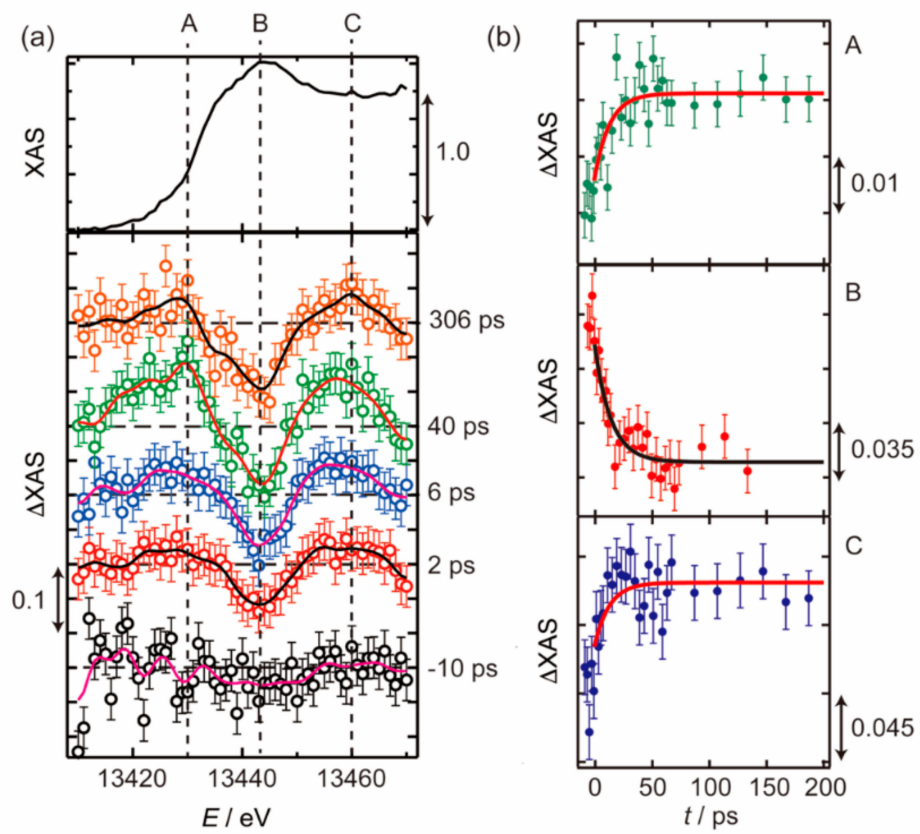

Figure 5. (a) Bi $\mathrm{L}_{3} \mathrm{X}$-ray absorption near edge structure (XANES) spectrum of the ground-state and difference XANES spectra ( $\triangle \mathrm{XAS}$ ) of the excited $\left(\mathrm{XAS}_{\mathrm{ex}}\right)$ and ground-states $\left(\mathrm{XAS}_{\mathrm{gs}}\right)$, with the corresponding delay time displayed beside each spectrum. (b) X-ray absorption intensities at points A, $B$, and C shown in (a) as a function of time (excited at $400 \mathrm{~nm}$ ). The figure was reproduced from [19] with permission of the Royal Chemical Society.

It would be interesting to observe the photocarrier behavior upon excitation with a $480 \mathrm{~nm}$ laser, of which the energy is close to the photoabsorption threshold of $\mathrm{BiVO}_{4}$, to understand the energy dependence of the photoexcitation dynamics of $\mathrm{BiVO}_{4}$. Figure 6a shows $\mathrm{Bi}_{3}$ edge difference spectra between the photoexcited state and the ground-state of $\mathrm{BiVO}_{4}$. The three peaks $(\mathrm{A}, \mathrm{B}$, and $\mathrm{C})$ appeared, as in the $400 \mathrm{~nm}$ excitation experiment. Note that peaks $A$ and $C$ appeared clearly at 2 ps in addition to peak B. Figure $6 \mathrm{~b}$ shows the kinetic traces of the Peaks A, B, and C. Kinetic constants were estimated using a single exponential function to be $4 \pm 1 \mathrm{ps}, 6 \pm 2 \mathrm{ps}$, and $5 \pm 1$ ps for peaks A, B, and $C$, respectively. These values were shorter than those obtained from the $400 \mathrm{~nm}$ excitation spectra. This difference in the time constant could be understood in terms of the extra energy difference of the photoexcited electrons. The $400 \mathrm{~nm}$ laser could excite electrons from the valence band (mainly oxygen) to the higher energy level in the conduction band (mainly $\mathrm{V}$ orbitals). The photoexcited electron relaxed to the bottom of the conduction band (composed of mainly $\mathrm{V} \mathrm{d}$ orbitals), releasing extra energy through the excitation of coherent vibrations or other lattice excitations. The electrons at the bottoms of $\mathrm{V} \mathrm{d}$ bands induced structural change around $\mathrm{V}$ which was monitored by the change of the $\mathrm{Bi}_{3}$ edge. In the case of excitation at $480 \mathrm{~nm}$, the extra energy of the photoexcited electrons was small and easily released to reach the bottom of the $\mathrm{V}$ conduction band to induce the structural change at the earlier stage. 


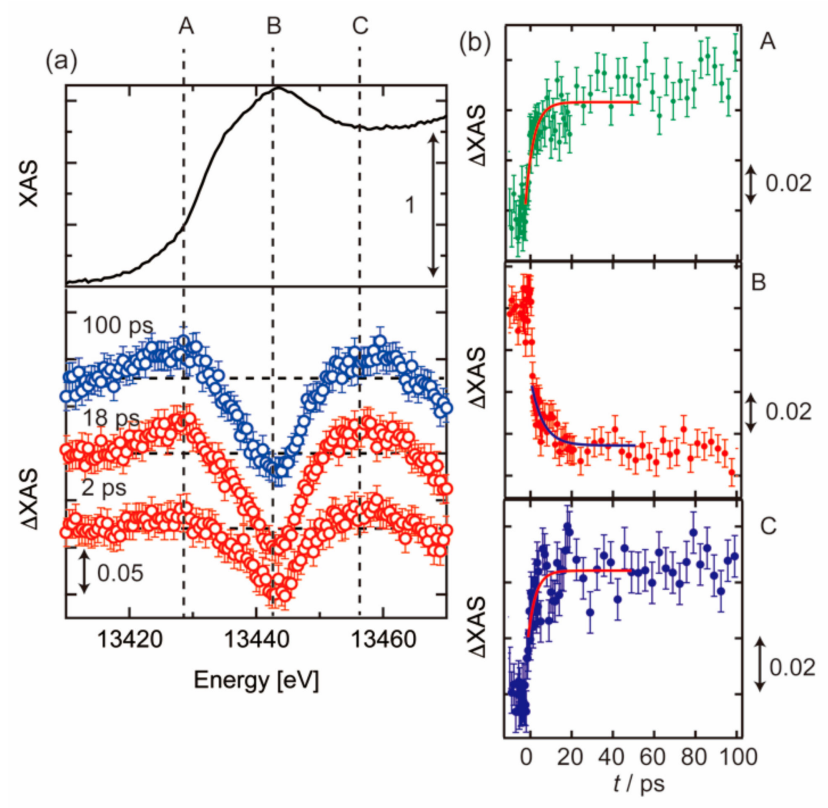

Figure 6. Bi $\mathrm{L}_{3}$ XANES spectrum of the ground-state and difference XANES spectra ( $\triangle \mathrm{XAS}$ ) of the excited $\left(\mathrm{XAS}_{\mathrm{ex}}\right)$ and ground-states $\left(\mathrm{XAS}_{\mathrm{gs}}\right)$, with the corresponding delay time displayed beside each spectrum. (b) X-ray absorption intensities at points A, B, and C displayed in (a) as a function of time (excited at $480 \mathrm{~nm}$ ).

\section{Summary and Perspective}

\subsection{Photoexcited States of Photocatalysts}

The photoexcited states of $\mathrm{WO}_{3}$ and $\mathrm{BiVO}_{4}$ photocatalysts were observed using the pump-probe XAFS method. The stage of the photoexcitation process earlier than $500 \mathrm{fs}$ was successfully observed using ATM. The photoexcited electrons in a higher energy level than the bottom of the conduction level induced a shift of the $\mathrm{W} \mathrm{L}_{3}$ edge to the negative side. The photoexcited electrons then reached the bottom of the conduction band around $700 \mathrm{fs}$ where the lowest-lying $\mathrm{W} \mathrm{d}$ orbitals were present. The electrons at the bottom of conduction band induced an anisotropic structural distortion to produce the metastable state up to $150 \mathrm{ps}$, as demonstrated by theoretical calculations of the $\mathrm{W} \mathrm{L}_{1}$ edge XANES. On the other hand, in the photoexcited state of $\mathrm{BiVO}_{4}$, there was no edge shift observed in the Bi $\mathrm{L}_{3}$-edge XAFS, which indicates that not the $\mathrm{Bi} 6 \mathrm{~s}$, but rather, the $\mathrm{O} 2 \mathrm{p}$ orbitals dominantly contributed

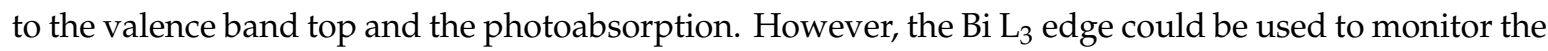
structural changes. At several tens of picoseconds, the $\mathrm{BiVO}_{4}$ reached the metastable state to stabilize the photoexcited electrons at V 3d. The time constants were dependent on the excitation wavelength, which reflected the different rate of release of the extra energy. In both systems, electron transfer from $\mathrm{O}$ to the cation and dynamic phonon processes (coherent vibration) occurred in less than $1 \mathrm{ps}$, followed by the structural changes in the 10-100 ps region to produce a metastable state and to stabilize the photoexcited electrons. These electrons may still have mobility and could contribute to photocatalytic reactions [68].

Structural changes around the photocarriers have previously been reported from the pump-probe XAFS methods $[15,26,27,69,70]$. Milne, Chergui, and colleagues reported structural changes around carrier trap sites in $\mathrm{TiO}_{2}$ [26] and Penfold et al. reported those in $\mathrm{ZnO}$ [15] by pump-probe XAFS using SRs. Obara et al. studied $\mathrm{TiO}_{2}$ by the ultrafast pump-probe XAFS and observed the absorption edge shift at $170 \mathrm{fs}$ by electron trapping in $\mathrm{TiO}_{2}$ followed by structural distortion near the surface at ca. $400 \mathrm{fs}$ after the photoexcitation in the SACLA [27]. It has been assumed that the photocarriers are localized at the trap sites (defects and/or surface). We consider that photocarriers can be located at the crystal lattice sites accompanied by local structure distortion such as a polaron. A structural distortion 
in $\alpha-\mathrm{Fe}_{2} \mathrm{O}_{3}$ was observed by Katz et al., which was related to polaron formation [69], and pump-probe $\mathrm{Fe} 3 \mathrm{p}$ absorption spectroscopy revealed that the polaron formation in $\alpha-\mathrm{Fe}_{2} \mathrm{O}_{3}$ occurred within $1 \mathrm{ps}$ after the photoexcitation [70].

\subsection{Advantage of Pump-Probe XAFS Techniques and Perspectives}

The pump-probe XAFS technique is unique compared to the other pump-probe methods in that XAFS can give a local picture of a specific element. Optical pump-probe methods typically provide information such as the life-time of photocarriers in the conduction and valence bands in k-space based on their absorption kinetics [71-73]. It is also possible to obtain transient lattice behavior from vibrational information [62]. On the other hand, XAFS can reveal the behavior of photoexcited materials in r-space. This can give local information around an X-ray absorbing atom with regard to the photoinduced changes of the structure and the electronic state. The absorbing atom can be regarded as an atomic-scale detector of photocarriers embedded in the material. It is thus possible that multi-edge measurements could be used to identify the roles and functions of each component. Although we measured only XAFS of heavy elements in this paper, it is feasible to observe transient XAS of light elements such as oxygen with a time resolution of 100-200 fs using soft XFELs [17,18,74]. Oxygen atoms mainly contribute to the valence band of photocatalysts, and it is possible to capture the transient hole behavior by O K-edge XAS. Although it was difficult to measure XAFS under the ambient conditions because of the large absorption of the soft X-rays by gas or liquid, recent instrumental developments have enabled even the in situ/operando measurement of O K-edge XAS [75]. In addition to soft XFELs, X-ray Raman is another candidate to observe the light element XAFS using hard $X$-rays [76,77]. Multi atom resonance X-ray Raman (MARX-Raman) is a new and potential candidate to selectively observe the light elements directly bound to a photoactive metal center, even in the presence of the same elements [78]. Developments of pump-probe XAFS techniques, not only in terms of simple absorption spectra for multi-elements, but also in RIXS and Raman, will uncover the nature of photocatalysts thoroughly in the r-space through the local structures and electronic states around photocarriers, which will provide a deeper understanding of photocatalysis and accelerate the development of novel photocatalysts.

Author Contributions: Y.U. is a main contributor of the paper. Y.U., T.Y. and K.A. conceived and planned the experiments and they interpret the results. T.K.: set up the SACLA experiments and Y.U. and T.K. conducted the experiment there. S.N. set up the PF-AR experiments and S.N. and Y.U. performed the experiments. All authors have read and agreed to the published version of the manuscript.

Funding: This work was financially supported by the Japan Society for the Promotion of Science (JSPS) through a Grant-in- Aid for Exploratory Research (No. 26620110), a Grant-in-Aid for Scientific Research (A) (No. 15H02173), a Grant-in-Aid for JSPS Research Fellow (No. 15J07459), grants for collaborative research in the Institute for Catalysis, Hokkaido University (Nos. 15A1004 and 18A1005) and a polymer membrane fuel cell project from the New Energy and Industrial Technology Development Organization (NEDO), Japan. This work is financially supported by Innovative Catalysis of CREST-JST program. This work was partially supported by the "X-ray Free Electron Laser Priority Strategic Program" and the "Photon and Quantum Basic Research Coordinated Development Program" of the Ministry of Education, Culture, Sports, Science and Technology (MEXT), Japan.

Acknowledgments: The authors appreciate all the collaborators who contributed to this work: Daiki Kido, Yuki Wakisaka, Satoru Takakusagi, Bunsho Ohtani (Hokkaido University), Akihiro Koide (Institute for Molecular Science), Yasuhiro Niwa, Kohei Ichiyanagi, Ryo Fukaya, Shin-ichi Adachi (Photon Factory, Institute for Materials Structure Science), Tadashi Togashi, Shigeki Owada, Yusaku Yamamoto, Misaki Katayama, Makina Yabashi (SPring-8, JASRI and SACLA, Riken), Keisuke Hatada (Toyama University), Akihide Iwase, Akihiko Kudo (Tokyo University of Science). We also appreciate Hebatalla Elnaggar (Utrecht University) for valuable comments and suggestions. The PF-AR experiments were carried out under the approval of PF-PAC (Photon Factory Advisory Committee; Proposal No. 2013 G166 and 2015G542). The XFEL experiments were performed at the BL3 beamline of SACLA with the approval of the Japan Synchrotron Radiation Research Institute (JASRI) (Proposal Nos. 2017B8020, 2017A8058, 2015A8039, 2016B8007, 2015A8039, and 2014B8044). Reproduced from Ref. [22] with permission from the Royal Society of Chemistry. Reproduced from Ref. [19] with permission from the Phys. Chem. Chem. Phys. CP Owner Societies.

Conflicts of Interest: The authors declare no conflict of interest. 


\section{References}

1. Frahm, R. New method for time dependent X-ray absorption studies. Rev. Sci. Instrum. 1989, 60, 2515. [CrossRef]

2. Matsushita, T.; Phizackerley, R.P. A Fast X-ray Absorption Spectrometer for Use with Synchrotron Radiation. Jpn. J. Appl. Phys. 1981, 20, 2223-2228. [CrossRef]

3. Sekizawa, O.; Uruga, T.; Takagi, Y.; Nitta, K.; Kato, K.; Tanida, H.; Uesugi, K.; Hoshino, M.; Ikenaga, E.; Takeshita, K.; et al. SPring-8 BL36XU: Catalytic Reaction Dynamics for Fuel Cells. J. Phys. Conf. Ser. 2016, 712, 012142. [CrossRef]

4. Nachtegaal, M.; Müller, O.; König, C.; Frahm, R. QEXAFS: Techniques and Scientific Applications for Time-Resolved XAS. X-ray Absorpt. X-ray Emiss. Spectrosc. 2016, 155-183. [CrossRef]

5. Smolentsev, G.; Guda, A.; Zhang, X.; Haldrup, K.; Andreiadis, E.S.; Chavarot-Kerlidou, M.; Canton, S.E.; Nachtegaal, M.; Artero, V.; Sundstrom, V. Pump-Flow-Probe X-ray Absorption Spectroscopy as a Tool for Studying Intermediate States of Photocatalytic Systems. J. Phys. Chem. C 2013, 117, 17367-17375. [CrossRef]

6. Thiel, D.J.; Livinins, P.; Stern, E.A.; Lewis, A. Microsecond-resolved XAFS of the triplet excited state of $\mathrm{Pt}_{2}\left(\mathrm{P}_{2} \mathrm{O}_{5} \mathrm{H}_{2}\right)^{4-}{ }_{4}$. Nature 1993, 362, 40-43. [CrossRef]

7. Mills, D.; Lewis, A.; Harootunian, A.; Huang, J.; Smith, B. Time-resolved X-ray absorption spectroscopy of carbon monoxide-myoglobin recombination after laser photolysis. Science 1984, 223, 811-813. [CrossRef]

8. Pham, V.-T.; Gawelda, W.; Zaushitsyn, Y.; Kaiser, M.; Grolimund, D.; Johnson, S.L.; Abela, R.; Bressler, C.; Chergui, M. Observation of the Solvent Shell Reorganization around Photoexcited Atomic Solutes by Picosecond X-ray Absorption Spectroscopy. J. Am. Chem. Soc. 2007, 129, 1530-1531. [CrossRef]

9. Nozawa, S.; Adachi, S.; Takahashi, J.I.; Tazaki, R.; Guérin, L.; Daimon, M.; Tomita, A.; Sato, T.; Chollet, M.; Collet, E. Developing 100 ps-resolved X-ray structural analysis capabilities on beamline NW14A at the Photon Factory Advanced Ring. J. Synchrotron Radiat. 2007, 14, 313-319. [CrossRef]

10. Saes, M.; Bressler, C.; Abela, R.; Grolimund, D.; Johnson, S.L.; Heimann, P.A.; Chergui, M. Observing Photochemical Transients by Ultrafast X-Ray Absorption Spectroscopy. Phys. Rev. Lett. 2003, 90, 047403. [CrossRef]

11. Jennings, G.; Jäger, W.J.H.; Chen, L.X. Application of a multi-element Ge detector in laser pump/x-ray probe time-domain x-ray absorption fine structure. Rev. Sci. Instrum. 2002, 73, 362. [CrossRef]

12. Chen, L.X.; Jäger, W.J.H.; Jennings, G.; Gosztola, D.J.; Munkholm, A.; Hessler, J.P. Capturing a Photoexcited Molecular Structure Through Time-Domain X-ray Absorption Fine Structure. Science 2001, 292, 262-264. [CrossRef] [PubMed]

13. Chergui, M.; Collet, E. Photoinduced Structural Dynamics of Molecular Systems Mapped by Time-Resolved X-ray Methods. Chem. Rev. 2017, 117, 11025-11065. [CrossRef]

14. Smolentsev, G.; Milne, C.J.; Guda, A.; Haldrup, K.; Szlachetko, J.; Azzaroli, N.; Cirelli, C.; Knopp, G.; Bohinc, R.; Menzi, S.; et al. Taking a snapshot of the triplet excited state of an OLED organometallic luminophore using X-rays. Nat. Commun. 2020, 11, 2131. [CrossRef]

15. Penfold, T.J.; Szlachetko, J.; Santomauro, F.G.; Britz, A.; Gawelda, W.; Doumy, G.; March, A.M.; Southworth, S.H.; Rittmann, J.; Abela, R.; et al. Revealing hole trapping in zinc oxide nanoparticles by time-resolved X-ray spectroscopy. Nat. Commun. 2018, 9, 478. [CrossRef] [PubMed]

16. Parchenko, S.; Paris, E.; McNally, D.; Abreu, E.; Dantz, M.; Bothschafter, E.M.; Reid, A.H.; Schlotter, W.F.; Lin, M.-F.; Wandel, S.F.; et al. Orbital dynamics during an ultrafast insulator to metal transition. Phys. Rev. Res. 2020, 2, 023110. [CrossRef]

17. Ismail, A.S.M.; Uemura, Y.; Park, S.H.; Kwon, S.; Kim, M.; Elnaggar, H.; Frati, F.; Niwa, Y.; Wadati, H.; Hirata, Y.; et al. Direct observation of the electronic states of photoexcited hematite with ultrafast 2p3d X-ray absorption spectroscopy and resonant inelastic X-ray scattering. Phys. Chem. Chem. Phys. 2020, 22, 2685-2692. [CrossRef] [PubMed]

18. Wernet, P.; Kunnus, K.; Josefsson, I.; Rajkovic, I.; Quevedo, W.; Beye, M.; Schreck, S.; Grubel, S.; Scholz, M.; Nordlund, D.; et al. Orbital-specific mapping of the ligand exchange dynamics of $\mathrm{Fe}(\mathrm{CO})_{5}$ in solution. Nature 2015, 520, 78-81. [CrossRef] [PubMed] 
19. Koide, A.; Uemura, Y.; Kido, D.; Wakisaka, Y.; Takakusagi, S.; Ohtani, B.; Niwa, Y.; Nozawa, S.; Ichiyanagi, K.; Fukaya, R.; et al. Photoinduced anisotropic distortion as the electron trapping site of tungsten trioxide by ultrafast W L1-edge X-ray absorption spectroscopy with full potential multiple scattering calculations. Phys. Chem. Chem. Phys. 2020, 22, 2615-2621. [CrossRef] [PubMed]

20. Uemura, Y.; Uehara, H.; Niwa, Y.; Nozawa, S.; Sato, T.; Adachi, S.; Ohtani, B.; Takakusagi, S.; Asakura, K. In Situ Picosecond XAFS Study of an Excited State of Tungsten Oxide. Chem. Lett. 2014, 43, 977-979. [CrossRef]

21. Uemura, Y.; Kido, D.; Wakisaka, Y.; Uehara, H.; Ohba, T.; Niwa, Y.; Nozawa, S.; Sato, T.; Ichiyanagi, K.; Fukaya, R.; et al. Dynamics of photoelectrons and structural changes of tungsten trioxide observed by femtosecond transient XAFS. Angew. Chem. Int. Ed. 2016, 55, 1364-1367. [CrossRef]

22. Uemura, Y.; Kido, D.; Koide, A.; Wakisaka, Y.; Niwa, Y.; Nozawa, S.; Ichiyanagi, K.; Fukaya, R.; Adachi, S.; Katayama, T.; et al. Capturing local structure modulations of photoexcited $\mathrm{BiVO}_{4}$ by ultrafast transient XAFS. Chem. Commun. 2017, 53, 7314-7317. [CrossRef]

23. Ohtani, B. Photocatalysis A to Z-What we know and what we do not know in a scientific sense. J. Photochem. Photobiol. C 2010, 11, 157-178. [CrossRef]

24. Ohtani, B. Hidden but Possibly Fatal Misconceptions in Photocatalysis Studies: A Short Critical Review. Catalysts 2016, 6, 192. [CrossRef]

25. Wang, Z.; Li, C.; Domen, K. Recent developments in heterogeneous photocatalysts for solar-driven overall water splitting. Chem. Soc. Rev. 2019, 48, 2109-2125. [CrossRef] [PubMed]

26. Rittmann-Frank, M.H.; Milne, C.J.; Rittmann, J.; Reinhard, M.; Penfold, T.J.; Chergui, M. Mapping of the Photoinduced Electron Traps in $\mathrm{TiO}_{2}$ by Picosecond X-ray Absorption Spectroscopy. Angew. Chem. Int. Ed. 2014, 53, 5858-5862. [CrossRef]

27. Obara, Y.; Ito, H.; Ito, T.; Kurahashi, N.; Thürmer, S.; Tanaka, H.; Katayama, T.; Togashi, T.; Owada, S.; Yamamoto, Y. Femtosecond time-resolved X-ray absorption spectroscopy of anatase $\mathrm{TiO}_{2}$ nanoparticles using XFEL. Struct. Dyn. 2017, 4, 044033. [CrossRef]

28. Abe, R.; Takami, H.; Murakami, N.; Ohtani, B. Pristine Simple Oxides as Visible Light Driven Photocatalysts: Highly Efficient Decomposition of Organic Compounds over Platinum-Loaded Tungsten Oxide. J. Am. Chem. Soc. 2008, 130, 7780-7781. [CrossRef]

29. Abe, R.; Takata, T.; Sugihara, H.; Domen, K. Photocatalytic overall water splitting under visible light by $\mathrm{TaON}$ and $\mathrm{WO}_{3}$ with an $\mathrm{IO}_{3}{ }^{-} / \mathrm{I}^{-}$shuttle redox mediator. Chem. Commun. 2005, 3829-3831. [CrossRef]

30. Kudo, A.; Omori, K.; Kato, H. A Novel Aqueous Process for Preparation of Crystal Form-Controlled and Highly Crystalline $\mathrm{BiVO}_{4}$ Powder from Layered Vanadates at Room Temperature and Its Photocatalytic and Photophysical Properties. J. Am. Chem. Soc. 1999, 121, 11459-11467. [CrossRef]

31. Iwase, A.; Kudo, A. Photoelectrochemical water splitting using visible-light-responsive $\mathrm{BiVO}_{4}$ fine particles prepared in an aqueous acetic acid solution. J. Mater. Chem. 2010, 20, 7536-7542. [CrossRef]

32. Sato, T.; Nozawa, S.; Tomita, A.; Hoshino, M.; Koshihara, S.; Fujii, H.; Adachi, S. Coordination and Electronic Structure of Ruthenium(II)-tris-2,2'-bipyridine in the Triplet Metal-to-Ligand Charge-Transfer Excited State Observed by Picosecond Time-Resolved Ru K-Edge XAFS. J. Phys. Chem. C 2012, 116, 14232-14236. [CrossRef]

33. Nozawa, S.; Sato, T.; Chollet, M.; Ichiyanagi, K.; Tomita, A.; Fujii, H.; Adachi, S.-I.; Koshihara, S.-Y. Direct Probing of Spin State Dynamics Coupled with Electronic and Structural Modifications by Picosecond Time-Resolved XAFS. J. Am. Chem. Soc. 2010, 132, 61-63. [CrossRef]

34. Kim, J.G.; Nozawa, S.; Kim, H.; Choi, E.H.; Sato, T.; Kim, T.W.; Kim, K.H.; Ki, H.; Kim, J.; Choi, M.; et al. Mapping the emergence of molecular vibrations mediating bond formation. Nature 2020, 582, 520-524. [CrossRef] [PubMed]

35. Kim, K.H.; Kim, J.G.; Nozawa, S.; Sato, T.; Oang, K.Y.; Kim, T.W.; Ki, H.; Jo, J.; Park, S.; Song, C.; et al. Direct observation of bond formation in solution with femtosecond X-ray scattering. Nature 2015, 518, 385-389. [CrossRef]

36. Ichiyanagi, K.; Takagi, S.; Kawai, N.; Fukaya, R.; Nozawa, S.; Nakamura, K.G.; Liss, K.-D.; Kimura, M.; Adachi, S. Microstructural deformation process of shock-compressed polycrystalline aluminum. Sci. Rep. 2019, 9, 7604. [CrossRef]

37. Sato-Tomita, A.; Shibayama, N. Size and Shape Controlled Crystallization of Hemoglobin for Advanced Crystallography. Crystals 2017, 7, 282. [CrossRef] 
38. Nozawa, S. Upgrade the Beamline PF-AR NW14A for the High-Repetition-Rate X-Ray Pump-Probe Experiments. In Proceedings of the Mechanical Engineering Design of Synchrotron Radiation Equipment and Instrumentation Conference, Barcelona, Spain, 11-16 September 2017; pp. 351-352.

39. Yabashi, M.; Katayama, T. XFEL. In XAFS Techniques for Catalysts, Nanomaterals and Surfaces; Iwasawa, Y., Asakura, K., Tada, M., Eds.; Springer: Berlin/Heidelberg, Germany, 2016; p. 63.

40. Tono, K.; Togashi, T.; Inubushi, Y.; Sato, T.; Katayama, T.; Ogawa, K.; Ohashi, H.; Kimura, H.; Takahashi, S.; Takeshita, K.; et al. Beamline, experimental stations and photon beam diagnostics for the hard x-ray free electron laser of SACLA. New J. Phys. 2013, 15, 083035. [CrossRef]

41. Ishikawa, T.; Aoyagi, H.; Asaka, T.; Asano, Y.; Azumi, N.; Bizen, T.; Ego, H.; Fukami, K.; Fukui, T.; Furukawa, Y.; et al. A compact X-ray free-electron laser emitting in the sub-ångström region. Nat. Photonics 2012, 6, 540-544. [CrossRef]

42. Katayama, T.; Nozawa, S.; Umena, Y.; Lee, S.; Togashi, T.; Owada, S.; Yabashi, M. A versatile experimental system for tracking ultrafast chemical reactions with X-ray free-electron lasers. Struct. Dyn. 2019, 6, 054302. [CrossRef]

43. Katayama, T.; Northey, T.; Gawelda, W.; Milne, C.J.; Vankó, G.; Lima, F.A.; Bohinc, R.; Németh, Z.; Nozawa, S.; Sato, T; et al. Tracking multiple components of a nuclear wavepacket in photoexcited $\mathrm{Cu}(\mathrm{I})$-phenanthroline complex using ultrafast $X$-ray spectroscopy. Nat. Commun. 2019, 10, 3606. [CrossRef]

44. Ogi, Y.; Obara, Y.; Katayama, T.; Suzuki, Y.I.; Liu, S.Y.; Bartlett, N.C.M.; Kurahashi, N.; Karashima, S.; Togashi, T.; Inubushi, Y.; et al. Ultraviolet photochemical reaction of $\left[\mathrm{Fe}(\mathrm{III})\left(\mathrm{C}_{2} \mathrm{O}_{4}\right)_{3}\right]^{3-}$ in aqueous solutions studied by femtosecond time-resolved $\mathrm{X}$-ray absorption spectroscopy using an X-ray free electron laser. Struct. Dyn. 2015, 2, 034901. [CrossRef]

45. Kinschel, D.; Bacellar, C.; Cannelli, O.; Sorokin, B.; Katayama, T.; Mancini, G.F.; Rouxel, J.R.; Obara, Y.; Nishitani, J.; Ito, H.; et al. Femtosecond X-ray emission study of the spin cross-over dynamics in haem proteins. Nat. Commun. 2020, 11, 4145. [CrossRef]

46. Katayama, T.; Hirano, T.; Morioka, Y.; Sano, Y.; Osaka, T.; Owada, S.; Togashi, T.; Yabashi, M. X-ray optics for advanced ultrafast pump-probe $X$-ray experiments at SACLAThis article will form part of a virtual special issue on X-ray free-electron lasers. J. Synchrotron Radiat. 2019, 26, 333-338. [CrossRef]

47. Kameshima, T.; Ono, S.; Kudo, T.; Ozaki, K.; Kirihara, Y.; Kobayashi, K.; Inubushi, Y.; Yabashi, M.; Horigome, T.; Holland, A.; et al. Development of an X-ray pixel detector with multi-port charge-coupled device for X-ray free-electron laser experiments. Rev. Sci. Instrum. 2014, 85, 033110. [CrossRef] [PubMed]

48. Kudo, T.; Tono, K.; Yabashi, M.; Togashi, T.; Sato, T.; Inubushi, Y.; Omodani, M.; Kirihara, Y.; Matsushita, T.; Kobayashi, K.; et al. A photodiode amplifier system for pulse-by-pulse intensity measurement of an X-ray free electron laser. Rev. Sci. Instrum. 2012, 83, 043108. [CrossRef]

49. Katayama, T.; Inubushi, Y.; Obara, Y.; Sato, T.; Togashi, T.; Tono, K.; Hatsui, T.; Kameshima, T.; Bhattacharya, A.; Ogi, Y.; et al. Femtosecond x-ray absorption spectroscopy with hard x-ray free electron laser. Appl. Phys. Lett. 2013, 103, 131105. [CrossRef]

50. Katayama, T.; Owada, S.; Togashi, T.; Ogawa, K.; Karvinen, P.; Vartiainen, I.; Eronen, A.; David, C.; Sato, T.; Nakajima, K.; et al. A beam branching method for timing and spectral characterization of hard X-ray free-electron lasers. Struct. Dyn. 2016, 3, 034301. [CrossRef]

51. Bamwenda, G.R.; Uesigi, T.; Abe, Y.; Sayama, K.; Arakawa, H. The photocatalytic oxidation of water to $\mathrm{O}_{2}$ over pure $\mathrm{CeO}_{2}, \mathrm{WO}_{3}$, and $\mathrm{TiO}_{2}$ using $\mathrm{Fe}^{3+}$ and $\mathrm{Ce}^{4+}$ as electron acceptors. Appl. Catal. A 2001, 205, 117-128. [CrossRef]

52. Asakura, H.; Shishido, T.; Yamazoe, S.; Teramura, K.; Tanaka, T. Structural Analysis of Group V, VI, and VII Metal Compounds by XAFS. J. Phys. Chem. C 2011, 115, 23653-23663. [CrossRef]

53. Yamazoe, S.; Hitomi, Y.; Shishido, T.; Tanaka, T. XAFS Study of Tungsten $\mathrm{L}_{1}$ - and $\mathrm{L}_{3}$-Edges: Structural Analysis of $\mathrm{WO}_{3}$ Species Loaded on $\mathrm{TiO}_{2}$ as a Catalyst for Photooxidation of $\mathrm{NH}_{3}$. J. Phys. Chem. C 2008, 112, 6869-6879. [CrossRef]

54. Hatada, K.; Hayakawa, K.; Benfatto, M.; Natoli, C.R. Full-potential multiple scattering theory with space-filling cells for bound and continuum states. J. Phys. Condens. Matter 2010, 22, 185501. [CrossRef]

55. Tokunaga, S.; Kato, H.; Kudo, A. Selective Preparation of Monoclinic and Tetragonal $\mathrm{BiVO}_{4}$ with Scheelite Structure and Their Photocatalytic Properties. Chem. Mater. 2001, 13, 4624-4628. [CrossRef]

56. Yu, J.; Kudo, A. Effects of Structural Variation on the Photocatalytic Performance of Hydrothermally Synthesized $\mathrm{BiVO}_{4}$. Adv. Funct. Mater. 2006, 16, 2163-2169. [CrossRef] 
57. Berglund, S.P.; Rettie, A.J.E.; Hoang, S.; Mullins, C.B. Incorporation of Mo and W into nanostructured BiVO4 films for efficient photoelectrochemical water oxidation. Phys. Chem. Chem. Phys. 2012, 14, 7065-7075. [CrossRef]

58. Kim, T.W.; Choi, K.-S. Nanoporous $\mathrm{BiVO}_{4}$ Photoanodes with Dual-Layer Oxygen Evolution Catalysts for Solar Water Splitting. Science 2014, 343, 990-994. [CrossRef]

59. Sharp, I.D.; Cooper, J.K.; Toma, F.M.; Buonsanti, R. Bismuth Vanadate as a Platform for Accelerating Discovery and Development of Complex Transition-Metal Oxide Photoanodes. ACS Energy Lett. 2017, 2, 139-150. [CrossRef]

60. Walsh, A.; Yan, Y.; Huda, M.N.; Al-Jassim, M.M.; Wei, S.-H. Band Edge Electronic Structure of BiVO4: Elucidating the Role of the Bi s and V d Orbitals. Chem. Mater. 2009, 21, 547-551. [CrossRef]

61. Cooper, J.K.; Gul, S.; Toma, F.M.; Chen, L.; Glans, P.-A.; Guo, J.; Ager, J.W.; Yano, J.; Sharp, I.D. Electronic Structure of Monoclinic BiVO 4 . Chem. Mater. 2014, 26, 5365-5373. [CrossRef]

62. Aiga, N.; Jia, Q.; Watanabe, K.; Kudo, A.; Sugimoto, T.; Matsumoto, Y. Electron-Phonon Coupling Dynamics at Oxygen Evolution Sites of Visible-Light-Driven Photocatalyst: Bismuth Vanadate. J. Phys. Chem. C 2013, 117, 9881-9886. [CrossRef]

63. Ravensbergen, J.; Abdi, F.F.; van Santen, J.H.; Frese, R.N.; Dam, B.; van de Krol, R.; Kennis, J.T.M. Unraveling the Carrier Dynamics of $\mathrm{BiVO}_{4}$ : A Femtosecond to Microsecond Transient Absorption Study. J. Phys. Chem. C 2014, 118, 27793-27800. [CrossRef]

64. Butler, K.T.; Dringoli, B.J.; Zhou, L.; Rao, P.M.; Walsh, A.; Titova, L.V. Ultrafast carrier dynamics in $\mathrm{BiVO}_{4}$ thin film photoanode material: Interplay between free carriers, trapped carriers and low-frequency lattice vibrations. J. Mater. Chem. A 2016, 4, 18516-18523. [CrossRef]

65. Ziwritsch, M.; Müller, S.; Hempel, H.; Unold, T.; Abdi, F.F.; van de Krol, R.; Friedrich, D.; Eichberger, R. Direct Time-Resolved Observation of Carrier Trapping and Polaron Conductivity in $\mathrm{BiVO}_{4}$. ACS Energy Lett. 2016, 1, 888-894. [CrossRef]

66. Grigioni, I.; Stamplecoskie, K.G.; Selli, E.; Kamat, P.V. Dynamics of Photogenerated Charge Carriers in $\mathrm{WO}_{3} / \mathrm{BiVO}_{4}$ Heterojunction Photoanodes. J. Phys. Chem. C 2015, 119, 20792-20800. [CrossRef]

67. Nan, J.; John, C.H.S. Can near-edge structure of the Bi L 3 edge determine the formal valence states of Bi? J. Phys. Condens. Matter 2006, 18, 8029.

68. Rettie, A.J.E.; Chemelewski, W.D.; Emin, D.; Mullins, C.B. Unravelling Small-Polaron Transport in Metal Oxide Photoelectrodes. J. Phys. Chem. Lett. 2016, 7, 471-479. [CrossRef]

69. Katz, J.E.; Zhang, X.; Attenkofer, K.; Chapman, K.W.; Frandsen, C.; Zarzycki, P.; Rosso, K.M.; Falcone, R.W.; Waychunas, G.A.; Gilbert, B. Electron Small Polarons and Their Mobility in Iron (Oxyhydr)oxide Nanoparticles. Science 2012, 337, 1200-1203. [CrossRef]

70. Carneiro, L.M.; Cushing, S.K.; Liu, C.; Su, Y.; Yang, P.; Alivisatos, A.P.; Leone, S.R. Excitation-wavelengthdependent small polaron trapping of photoexcited carriers in $\alpha-\mathrm{Fe}_{2} \mathrm{O}_{3}$. Nat. Mater. 2017, 16, 819-825. [CrossRef]

71. Bedja, I.; Hotchandani, S.; Kamat, P.V. Photoelectrochemistry of quantized tungsten trioxide colloids: Electron storage, electrochromic, and photoelectrochromic effects. J. Phys. Chem. 1993, 97, 11064-11070. [CrossRef]

72. Pesci, F.M.; Cowan, A.J.; Alexander, B.D.; Durrant, J.R.; Klug, D.R. Charge Carrier Dynamics on Mesoporous $\mathrm{WO}_{3}$ during Water Splitting. J. Phys. Chem. Lett. 2011, 2, 1900-1903. [CrossRef]

73. Amano, F.; Ishinaga, E.; Yamakata, A. Effect of Particle Size on the Photocatalytic Activity of $\mathrm{WO}_{3}$ Particles for Water Oxidation. J. Phys. Chem. C 2013, 117, 22584-22590. [CrossRef]

74. Park, S.H.; Kim, M.; Min, C.-K.; Eom, I.; Nam, I.; Lee, H.-S.; Kang, H.-S.; Kim, H.-D.; Jang, H.Y.; Kim, S.; et al. PAL-XFEL soft $X$-ray scientific instruments and X-ray optics: First commissioning results. Rev. Sci. Instrum. 2018, 89, 055105. [CrossRef]

75. Shavorskiy, A.; Ye, X.; Karslıoğlu, O.; Poletayev, A.D.; Hartl, M.; Zegkinoglou, I.; Trotochaud, L.; Nemšák, S.; Schneider, C.M.; Crumlin, E.J.; et al. Direct Mapping of Band Positions in Doped and Undoped Hematite during Photoelectrochemical Water Splitting. J. Phys. Chem. Lett. 2017, 8, 5579-5586. [CrossRef] [PubMed]

76. Tohji, K.; Udagawa, Y. Novel approach for structure analysis by x-ray Raman scattering. Phys. Rev. B Condens. Matter 1987, 36, 9410-9412. [CrossRef] 
77. Bergmann, U.; Groenzin, H.; Mullins, O.C.; Glatzel, P.; Fetzer, J.; Cramer, S.P. Carbon K-edge X-ray Raman spectroscopy supports simple, yet powerful description of aromatic hydrocarbons and asphaltenes. Chem. Phys. Lett. 2003, 369, 184-191. [CrossRef]

78. Sirisit, N.; Kido, D.; Wakisaka, Y.; Ariga-Miwa, H.; Takakusagi, S.; Asakura, K.; Sekizawa, O.; Sakata, T.; Uruga, T.; Iwasawa, Y. Evidence for Multi-Atom Resonance X-ray Raman Spectroscopy-An in situ Low Z-element and Bond-specific X-ray Spectroscopy. e-J. Surf. Sci. Nanotechnol. 2018, 16, 387-390. [CrossRef]

Publisher's Note: MDPI stays neutral with regard to jurisdictional claims in published maps and institutional affiliations.

(C) 2020 by the authors. Licensee MDPI, Basel, Switzerland. This article is an open access article distributed under the terms and conditions of the Creative Commons Attribution (CC BY) license (http://creativecommons.org/licenses/by/4.0/). 